\title{
Is a hypothetical melanoma-like neuromelanin the underlying factor essential for the aetiopathogenesis and clinical manifestations of multiple sclerosis?
}

Bernd Krone $e^{1,2^{*}+}$ and John M Grange $e^{3+}$

\begin{abstract}
Background: Multiple sclerosis (MS) has undergone a significant increase in incidence in the industrialised nations over the last 130 years. Changing environmental factors, possibly infections or a lack of or altered timing of them, determine the prevalence of the disease. Although a plethora of aetiological factors, clearly evident in a group of children with MS, appear relevant, there may nevertheless be a single factor essential for the aetiopathogenesis and clinical manifestation of MS.

Description and discussion: This hitherto unknown factor is postulated to be a 'melanoma-like neuromelanin' (MLN) dependent on the activation of a gene for syncytin-1. An involvement of MLN could explain the diverse findings in the epidemiology, immunology and pathology of MS, requiring a consideration of a complex infectious background, the human leucocyte antigens, as well as cosmic radiation causing geomagnetic disturbances, vitamin D deficiency, smoking, and lower levels of uric acid.

Summary: In principle, the MLN-based concept is a unifying one, capable of explaining a number of characteristics of the disease. To date, MLN has not been addressed in studies on MS and future work will need to be done on human patients, as there is little or no neuromelanin (the precursor of MLN) in the animals used as experimental models in the study of MS.
\end{abstract}

Keywords: Multiple sclerosis, Risk factors, Latency, Melanoma, Neuro-melanin, Epstein-Barr virus, Human endogenous retrovirus, Vitamin D, Geomagnetic disturbances

\section{Background}

The recent paper by Sajedi and Abdollahi in this journal [1] on geomagnetic disturbances as a risk factor for multiple sclerosis (MS) emphasises the complexity of the pathogenesis of this disease but also encourages a search for an underlying factor that could be affected by such disturbances and other risk factors. A recent broadranging epidemiologic study also focuses attention on the aetiology of multiple sclerosis and facilitates a

\footnotetext{
* Correspondence: bernd-krone@t-online.de

${ }^{\dagger}$ Equal contributors

'Institute of Virology, University of Göttingen, Kreuzbergring 57, 37075

Göttingen, Germany

${ }^{2}$ Medical Laboratory, Kurt Reuber-Haus, Herkulesstraße 34a, 34119 Kassel, Germany

Full list of author information is available at the end of the article
}

reappraisal of the putative risk factors [2]. The outstanding question is whether, among the plethora of described possible aetiological factors for MS, there is a single, hitherto undescribed, risk factor that is essential for the entire course of the disease process from the initiating events to clinical manifestation.

\begin{abstract}
Aim of the debate
In response to this issue, we emphasise that the complex epidemiology does indeed point to a plethora of concomitant factors in MS. Moreover, further enigmas, in particular the wide variation in age of onset and the occurrence of latency and relapses require, for their explanation, an endogenous underlying risk factor essential for the pathogenesis and clinical manifestation of the
\end{abstract}

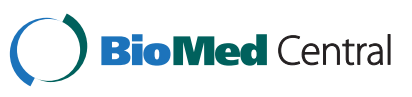


disease. In this paper we propose one such putative factor, a 'melanoma-like neuromelanin' (MLN), the involvement of which is supported by the available epidemiological data, and we discuss the relevance of this factor to the interpretation of past and current studies on MS and on the possible direction of future studies. The many factors postulated to play a role in the aetiology of MS are summarised in Table 1, according to the strength of the evidence. The candidate factors with possible relevance in MS will be considered only in relation to MLN. Alternative and/or additional influences of these factors [3] are included in Table 1 but are largely beyond the scope of this debate.

It is, however, important to note that the quality of the evidence for the relevance of the many described factors to the pathogenesis and clinical outcome of MS varies considerably. To guide the reader, we make clear in the Table 1 those observations that are supported by firm evidence. All interpretations in the text beyond the section 'Evidence for concomitant effects' are only speculative but, again, those considered to be of key relevance for the proposed unifying concept are likewise highlighted $(\bullet \bullet \bullet=$ very relevant and $\bullet \bullet=$ relevant $)$.

\section{Evidence for concomitant effects}

An illustrative group of paediatric patients studied by Hanefeld and co-workers $[10,15,17,18]$ emphasises the wide range of factors of putative relevance in the pathogenesis of MS (Table 1, footnote $\mathbb{~}$ ). The most notable of these are evidence of past infection with Epstein-Barr virus (EBV) in virtually all patients $[10,60] \bullet \bullet \bullet$, and altered immune responses to infections with several other viruses, in particular with measles, varicella, and herpes simplex viruses

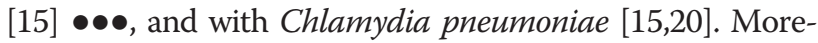
over, production of specific antibody against measles, rubella, varicella, EBV and herpes simplex viruses in the brain/cerebrospinal fluid is also a hallmark of MS $[17,18]$ - $\bullet$. Further observations reveal an association of MS risk with the season of birth, postulated to be related to low vitamin D levels experienced in utero (pre-birth) [19,30], exposure to visible light close to the time of onset of the disease [31,51] and, finally, a dependence of MS risk on female sex hormones that commences only in late childhood, becoming more pronounced in adolescence, and reaching maximal values in adults: with the girl:boy ratio on age at onset in young children $(<8$ years) being 1.2:1, compared with $3: 1$ in adults $[31,32]$. The described risk factors for MS, observed in parallel and numbering around 16, are listed in Table 1, footnote $\$$.

\section{Is a melanoma-like neuromelanin (MLN) the 'missing link'?} Current explanations as to how the diverse risk factors might cooperate to cause MS [3], fail to delineate any single candidate factor able to explain concomitance of factors operating at widely differing points or periods of time in life. There is, however, one - though still hypothetical - factor that is in principle able to form the basis of such time-spanning concomitance and we have already speculated that this is the 'missing link'; namely, a melanoma-like neuromelanin (MLN) [14], and this is supported by the fact that the initiating steps in MS as well as in melanoma [61] occur in cells derived from the neural crest. This encouraged us to seek for parallels in the aetiology of the two diseases, parallels that might be ascribed to the biosynthesis and action of a hypothetical melanomalike neuromelanin. In both diseases various environmental causative agents have been implicated in pathogenesis and some may combine, perhaps synergistically, to produce the respective disease. These include an overexpression of genes coding for the envelope proteins of human endogenous retroviruses (HERVs), of group W in MS [4-8] and of K in melanoma [62], although the increased amount of the HERV-W ENV protein (syncytin-1) in nerve tissue is neither a genetically determined risk nor a result of an infectious behavior of these elements with a viral ancestry, encoded by the human genome.

The importance of the establishment of protective immunoregulatory surveillance networks for the prevention of MS is emphasised by the so-called hygiene hypothesis. There is growing evidence from many sources that environmental factors in the industrialised nations that isolate the human population from contact with exogenous viral, microbial and parasitic stimuli that millions of years of evolution have led the immune system to 'expect' has led to a failure in the development of immunoregulatory networks and to an increase in incidence of several classes of disease characterised by chronic inflammation and autoimmune phenomena $[61,63]$. With particular relevance to MS, exposure to certain pathogens such as the Epstein-Barr virus which once regularly occurred in infancy now often occurs only years later $[10,12]$.

In the following sections we discuss the possible aetiological role of the hypothetical MLN, drawing parallels with melanoma, and the putative role of HERVs, Epstein-Barr virus, other infections and other noninfectious environmental factors $[3,33]$ that could affect the biosynthesis of MLN, possibly commencing even before birth. We also discuss its subsequent oxidative charging and discharging and its relationship to other described co-factors acting at quite different times in life that might also be involved throughout the pathological processes that finally determine the clinical manifestations of MS.

\section{Characterization of MLN}

Neuromelanins behave as quasi-polymeric redox-pigments [42]. Relatively large quantities are necessary for chemical 
Table 1 Environmental and genetic risk factors for multiple sclerosis

\begin{tabular}{lll}
\hline MS risk factor & Risk* $^{*}$ & Observations \\
\hline & & \\
& \\
Human endogenous & $\times \quad$ F & HERV-W and/or syncytin-1 more \\
retrovirus-W (HERV-W) & & frequently detectable/elevated in \\
& MS, increased levels of antibodies \\
& against HERV GAG and ENV \\
& antigens in MS, related to the \\
& activity of disease [4-8]
\end{tabular}

Postulated mechanism
1. Compromise of MS-protective
immune reactions favouring the immune reactions favo

Overexpression of the syncytin-1 gene encoded by HERV-W disturbs redox regulation in glial cells [9]

Time in life of infection with Epstein-Barr virus (EBV)

Involvement of infection with measles, varicella and herpes simplex viruses and with 12 or more other pathogens pneumoniae and/or human herpes virus-6

Worm infestation

Antihistamines

HLA-polymorphism

Interleukin-2 receptor a (IL-2Ra)

Interleukin-7 receptor a (IL-7Ra)

n-3-polyunsaturated fatty acids
G

P Main HLA class I molecule $A * 0201$ for the HLA-A0201 associated with a significantly reduced $M S$ risk (OR $=0.52, P=0.0015)[24]$ genomes of these agents in MS $[15,20,21]$ More frequent IgMspecific antibodies against Chlamydia pneumoniae in paediatric onset MS [15]

$E^{\bullet} \quad P \quad$ Worm infestation less frequent in MS and treatment of worm infections leads to relapse of MS [22]

$E^{w} \quad P$ Protective effects of antihistamines in MS [23]

G

P Mutations in IL-2Ra gene in MS more frequent [25]

G

P Mutations in IL-7Ra gene in MS more frequent [26]

E $\quad P$ Reduced MS risk with diet rich in n-3 poly-unsaturated fatty acids [27]
E $\S \quad F \quad$ More frequent detection of
Infection with EBV early in life can establish MS protective immunity $[3,10,11,14]$. Infection with EBV delayed in life after immune response against an epitope nested in FENIAEGLRALLARSHVER (partial sequence of EBNA-1) is primed (see next entry) to form $T$ - helper cells instead of regulatory T-cells essential for MS protection [14]

Immune responses against diverse agents generates MS-protection by cross-reaction of a self-specific CD8 ${ }^{+}$-T-cell response against a peptide MPVPSAPSTMPVPSAPST belonging to the human endogenous retrovirus W (HERV-W), encoded on the complementary DNA-strand of the syncytin-1 gene $[14,19]$

Persisting infections can prime immune response against an epitope nested in FENIAEGLRALLARSHVER (partial sequence of EBV EBNA-1) to induce T-helper cells [14]

Contributes an immune stimulatory context that favours the generation of regulatory T-cells

Antihistamines suppress unfavourable allergic reactions competing with 'anti-parasite'-like reactions

Ability of HLA-polymorphism for immune presentation of the peptide MPVPSAPSTMPVPSAPST is good such as with HLA-A0201 (frequency of about $30 \%$ in a European population) [14]

Component of the CD-25 molecule of regulatory T-cells, critical involvement of these cells in MSprotection

Important for maintenance of $\mathrm{CD}^{+}$-T-cell memory, critical is a long-persisting MS-protective cellular immune reaction

Dietary factors leading to an enrichment of ganglioside-content of T-cells. The MS-protective immune reaction seems to be an

(Irrespective of time in life): Clonal expansion of lymphocytes in the CNS, or EBV infection triggers autoimmunity via molecular mimicry

Alternative mechanism

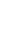




\begin{aligned} \hline Vitamin D-deficiency $\quad E \bullet \quad F \quad \begin{array}{l}\text { Month of birth-effect [30,31]. Low } \\ \text { levels of vitamin D in MS patients } \\ \text { [32-34] }\end{array}\end{aligned}$

immune repair mediated by

gangliosides [14,19,28,29]

\section{Factors favouring the biosynthesis of MLN not predominantly involving the immune system}

Deficiency pre-birth and after birth reduces intracellular glutathione [35]

Reduced exposure to sunlight rich in UV-B dependent on geographical latitude [3,32] risk increases with higher latitu $[3,32]$

Selenium deficiency

$E^{w} \quad F \quad M S$ more frequent in regions with low levels of selenium in soil $[36,37]$

Female sex hormones

E $\S \quad F \quad$ Dependence of MS risk on gender. MS risk in young children indepedent from gender but increased girl/boy rate in puberty $[31,32]$. Reduced MS risk in pregnancy, elevated MS risk after pregnancy and after the menopause [39]

Smoking

Iron-load

$E^{\bullet \bullet \quad F ~ H i g h e r ~ r i s k ~ o f ~ M S ~ i n ~ c i g a r e t t e ~}$ smokers [40]

E $\quad$ F MS association to eating of meat [27]. Iron accumulation early in MS plaques $[42,43]$

\begin{tabular}{|c|c|c|c|}
\hline \multirow[t]{2}{*}{ Vitamin D-deficiency } & $E^{\bullet \bullet \bullet}$ & $\mathrm{F}$ & See above \\
\hline & $\S$ & & \\
\hline Low sun exposure & $E^{\bullet \bullet}$ & $\mathrm{F}$ & See above \\
\hline Selenium deficiency & $E^{w}$ & $\mathrm{~F}$ & See above \\
\hline \multirow[t]{2}{*}{$\begin{array}{l}\text { Geomagnetic disturbances/ } \\
\text { Cosmic radiation }\end{array}$} & $E^{\bullet \bullet}$ & $\mathrm{F}$ & $\begin{array}{l}\text { MS relates to geomagnetic } 60^{\circ} \\
\text { latitude [1] }\end{array}$ \\
\hline & $E$ & $\mathrm{~F}$ & $\begin{array}{l}\text { MS association to mountain regions } \\
\text { [50] }\end{array}$ \\
\hline Visible light & $E \S$ & $P$ & $\begin{array}{l}\text { Increased risk of MS onset (1st } \\
\text { attack) in the lightest months of the } \\
\text { year }[31,51]\end{array}$ \\
\hline Psycho-physical trauma & $E$ & $\mathrm{~F}$ & $\begin{array}{l}\text { Increased MS risk in relations to } \\
\text { psycho-physical trauma, detection } \\
\text { of ROS-related products in MS [52] }\end{array}$ \\
\hline Heat/fever & $E$ & $\mathrm{~F}$ & $\begin{array}{l}\text { Heat as attack provoking factor in } \\
\text { MS }[53,54]\end{array}$ \\
\hline
\end{tabular}

Selenium deficiency reduces levels of the seleno-enzyme glutathioneperoxidase [38]

Syncytin-1 gene has a sensitivity for female sex hormones, (gene product has physiological role in placenta) [39]

Nicotine accumulates in melanin containing cells and interferes with melanin synthesis [41]

Melanoma-melanin is incorporating iron [44-48]

\section{Oxidative charging of MLN}

See above, glutathione is needed for discharging of MLN

See above, glutathione is needed for discharging of MLN

See above, glutathione-peroxidase is needed for discharging of MLN Iron containing MLN is charged by ionizing radiation/ cosmic radiation [49]. Cosmic radiation

\section{Physiological influence on} activity of neuromelanin

The hormone melatonin regulates the daily activity of neuromelanins (light-triggered day-night rhythm)

\section{Formation of short living} reactive oxygen species and radicals (ROS) by mitochondria

Traumatic events lead to the generation of ROS by mitochondria

\section{Dysregulation of the hypothalamic-pituary- adrenal axis}

Heat leads to the generation of ROS by mitochondria
Levels of vitamin D experienced in utero can have long-lasting effects on the development of numerous organ systems, including the CNS; during life, vitamin $D$ has clear immunomodulatory functions

Altered antigen reactivity, tolerance, epigenetic effects

Nitric oxide-mediated demyelination, axonal loss and epigenetic effects 


\section{Table 1 Environmental and genetic risk factors for multiple sclerosis (Continued)}

\begin{tabular}{|c|c|c|c|c|c|}
\hline & $E$ & $\mathrm{~F}$ & $\begin{array}{l}\text { MS protective effect of the } \\
\text { introduction of anti-pyretics [53] } \\
\text { and of the antibiotic penicillin [55] }\end{array}$ & $\begin{array}{l}\text { Fever leads to the generation of } \\
\text { ROS by mitochondria }\end{array}$ & \\
\hline \multirow[t]{2}{*}{ Chronic stress reaction } & $E^{w}$ & $\mathrm{~F}$ & $\begin{array}{l}\text { Decreased ubiquinone, and } \\
\text { increased endogenous digoxin and } \\
\text { metabolites of oxidative stress in } \\
\text { MS [56] }\end{array}$ & $\begin{array}{l}\text { Over-activation of the cellular } \\
\text { mevalonate pathway with decrease } \\
\text { of ubiquinone, and increase of } \\
\text { endogenous digoxin and ROS } \\
\text { production by mitochondria [56] }\end{array}$ & As above \\
\hline & & & & $\begin{array}{l}\text { 6. Formation of long-living } \\
\text { reactive oxygen species and } \\
\text { radicals (ROS) requiring typically } \\
\text { nitrogen oxide as a co-substrate }\end{array}$ & \\
\hline Infection/Inflammation & E & $F$ & $\begin{array}{l}\text { A small blood vessel is often } \\
\text { running through the plaque, the } \\
\text { end stage of MS pathology [57] }\end{array}$ & $\begin{array}{l}\text { Adherent polymorph nuclear cells } \\
\text { in small blood vessels form } \\
\text { nitrogen oxide (NO) that is not } \\
\text { readily cleared }\end{array}$ & \\
\hline Gout & E & $P$ & MS is extremely rare in patients & Radical scavenger function of uric & \\
\hline decreased uric acid & $E$ & F & $\begin{array}{l}\text { with gout and levels of uric acid are } \\
\text { about } 10 \text { to } 15 \% \text { lower in patients } \\
\text { with MS [58] }\end{array}$ & $\begin{array}{l}\text { acid for nitrogen-containing ROS } \\
\text { [58] }\end{array}$ & \\
\hline Glatiramer-acetate & E & $P$ & $\begin{array}{l}\text { An agent with therapeutic benefit } \\
\text { in MS }\end{array}$ & $\begin{array}{l}\text { Inhibition of NO synthase of } \\
\text { mononuclear cells [59] }\end{array}$ & \\
\hline \multicolumn{6}{|c|}{$\begin{array}{l}\text { Categorization of risks (see footnotes), observations, postulated mechanisms with respect to a hypothetical melanoma-like neuromelanin (MLN) ordered in groups } \\
\text { of } 6 \text { aspects, and alternative mechanisms as suggested in ref [32]. }\end{array}$} \\
\hline
\end{tabular}

analysis [43], and studies on small quantities of the various types of pigments have not, to our knowledge, been undertaken. Since, however, pathological forms of eumelanins of the skin, melanoma-like melanins, incorporate increased amounts of iron and other metals [44-48,64], it is likely that the presence of the hypothetical MLN would be detectable by determining iron levels in the relevant tissues $\bullet \bullet$. Iron has been detected in MS plaques and it has been shown by histopathology, three-dimensional enhanced $\mathrm{T} 2 \%$-weighted angiography, and other forms of nuclear magnetic resonance applicable to living persons, that iron is already present in the earliest stages of demyelinating disease, although iron levels showed no correlation with time elapsed since the initial clinical event nor with the degree of disability $[65,66]$.

Melanins, having diverse functions, are not primarily involved in the metabolism of reactive oxygen species and radicals (ROS) [45] since the membranes of the two organelles, mitochondria and melanosomes, are barriers for the migration at least of the negatively charged ROSanions. Although evidence for the existence of an equivalent of melanosome membranes in the brain is still missing $[67,68]$, it seems highly probable that the contact between a substantial amount of ROS and melanins results not only from an over-production and/or a failure of the destruction of ROS in the mitochondria but also when there is leakage of membranes that can be induced by the ROS themselves.
Melanins have the potential to act as quasi catalysts, becoming more oxidatively charged with every redoxreaction they participate in, so that they depend on systems for their subsequent reduction [45]. While the normal physiological forms of these pigments transform ROS to harmless oxygen species, abnormal oxidatively charged forms can generate harmful longer living species, in particular peroxynitrite $\bullet \bullet \bullet$.

Pathological forms of melanin, as encountered in melanomas, incorporate more iron [44-48], and are thus enabled to interact more profoundly with radiation. Whereas visible and ultraviolet light is transformed to heat (photon/phonon coupling), higher energy photons can cause photoionization which is dependent on the Fenton reaction of iron, Table 2 [69] $\bullet \bullet$. Upon dissipation of the absorbed energy the pigment becomes electrically and oxidatively charged [49] $\bullet \bullet$

Melanins can also be extremely long-lived [45] and this could, in principle, explain the concomitance of many factors in MS that operate over a wide range of time, from before birth and through early and later childhood until the onset of MS, typically in young adults.

\section{Environmental influences linked to the biogenesis and behavior of MLN}

The critical point in the biogenesis of MLN seems to be a high susceptibility to peroxides of the carbon-carbon 
Table 2 Five chemical reactions with supposed critical relevance in relation to MLN and MS

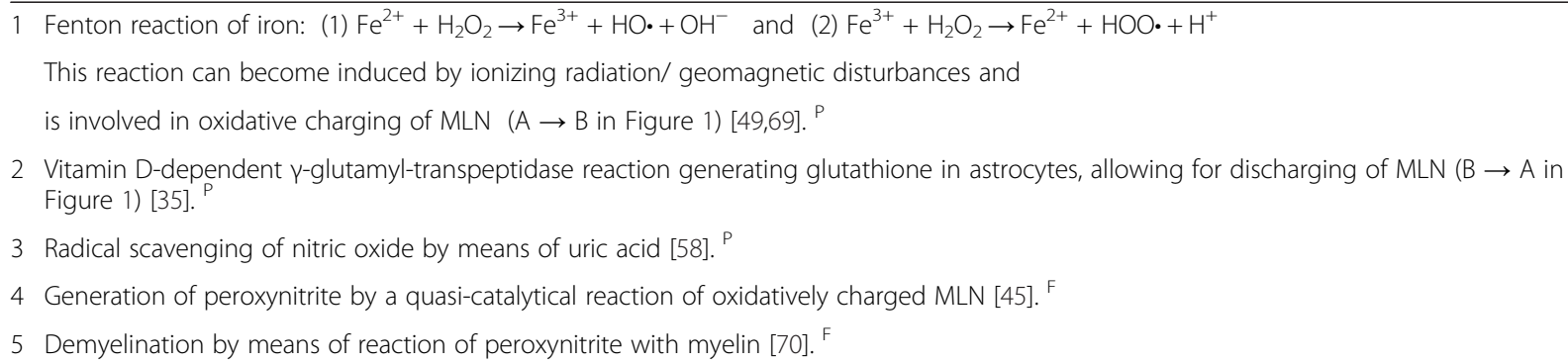

bond between the two carbonyl-groups of the (hypothetical) ortho-quinone structure in the melanin subunits [45] and its precursors $\bullet \bullet$ (Figure 1). Glutathione peroxidase as well as glutathione are needed to destroy all peroxides and a shortage of the enzyme is related to redox processes disturbed by syncytin-1 $[9,14]$.

Whereas the physiological neuromelanin pigment oscillates between the oxidised and reduced state, a hypothetical pathological form able to accumulate iron would have a greater amplitude of charging and a tendency to become pro-oxidatively charged (Figure 1). An oscillating process of oxidative charging and discharging of neuromelanin appears to be promoted by the combination of two equally important environmental effects, charging triggered by geomagnetic disturbances/cosmic radiation [1] and discharging by reduction equivalents that must be generated by the cells in a vitamin Ddependent manner [35]

The possible importance of geomagnetic disturbances/ cosmic radiation is supported by a recent meta-analysis that showed a significantly closer association of MS to $60^{\circ}$ magnetic latitude as compared with $60^{\circ}$ geographic latitude [1] $\bullet$. One consequence of this important study is that cosmic radiation on Earth's surface,

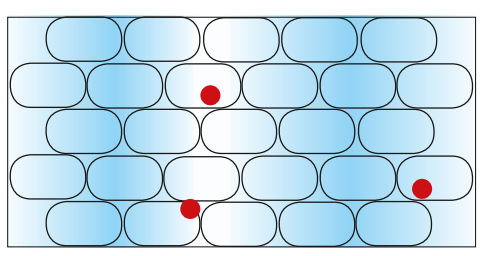

normal neuromelanin $\square=A$ or $B$

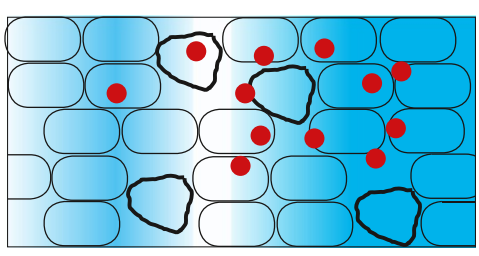

melanoma-like neuromelanin

$=\operatorname{iron}\left(\mathrm{Fe}^{2+}\right)$<smiles>O=C(O)C1Cc2cc(O)c(O)cc2N1</smiles><smiles>[C+][PH2+]C=C</smiles><smiles>[B]C1CC2=CC(=O)C(=O)C=C2N1</smiles><smiles>CCO</smiles><smiles>CC(=O)C1C/C(=C/C(=O)O)C(=CC(=O)O)N1</smiles>

Figure 1 Schematic description of normal neuromelanin and melanoma-like neuromelanin (MLN). Partial structures of the subunits $\mathbf{A}$ 5,6-dihydroxyindole-2-carboxylic acid, $\mathbf{B}$ : the oxidised ortho-quinone form, and $\mathbf{C}$ : an initial product formed upon reaction of $\mathbf{B}$ with $\mathrm{H}_{2} \mathrm{O}_{2}$; 'red point symbol': iron $\left(\mathrm{Fe}^{2+}\right)$. MLN has a greater tendency to become oxidatively charged (increased B/A-ratio) indicated in the background by stronger blue shading. 
although of low intensity (about $0.1 \mathrm{r} /$ year) cannot be described as biologically completely harmless. Another consequence of this study is that vitamin D can no longer be considered as the predominant MS risk factor $[3,33]$, although it must still be considered to be one of the several factors involved. Indeed this vitamin is likely to play a key role in MS as it is involved in the generation of reduction equivalents (glutathione) in the nerve cell, via $\gamma$-glutamyl-transpeptidase [35]. Crucially, the oxidative charging and discharging of MLN is an oscillating process, characteristic of a Belousov-Zhabotinsky reaction [71] that could logically explain the spatial and temporal manifestations of MS with plaques, attacks and remissions [19].

We postulate that a pro-oxidatively charged form of an altered melanin, namely MLN, is unable to destroy radicals and reactive oxygen species (ROS) released during abnormal mitochondrial activity (see below) but, instead, transforms them to more harmful long-living species, a process requiring nitrogen oxide (NO) as a co-substrate. Once formed, these abnormal longerliving species are responsible for demyelination in MS $[70] \bullet \bullet \bullet$.

\section{Underlying virological factors in the biogenesis of MLN}

It is highly probable that the biogenesis of a pathologic neuromelanin depends on a complex background that compromises the immunological control of the expression of an endogenous retroviral gene product, syncytin-1 [14], as an overexpression of this cellular component can disturb redox processes within the cell [9] and thus favour the biosynthesis of a melanoma-like neuromelanin (MLN). This could prove to be the link between MLN and the characteristic patterns of infections and associated T cell activity that we have described in our previous publications $[14,19]$. The available evidence points strongly to the root cause of MS being the overexpression of human endogenous retrovirus W (HERV-W) ENV coding for the syncytin-1 protein consequent to a complex immunological background centered on a past infection with Epstein-Barr

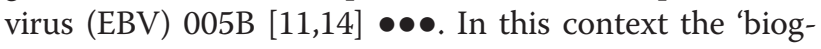
raphy' of the immune system [14] is of key relevance as an infection with EBV can compromise a MS-protective long-lasting cellular immune surveillance only after the immune response has been primed by other, prior, infections, in particular with Chlamydia pneumoniae $[10,14,60]$ and human herpes virus 6 [21].

As a consequence, a MS-protective immune response can become compromised $\bullet \bullet \bullet$. The specific candidate targets of the involved regulatory $\mathrm{T}$-cells $\left(\mathrm{T}_{\text {reg }} \mathrm{s}\right)$ and $\mathrm{CD}^{+}$-T-cells have been delineated [14], see also Table 1. $\mathrm{T}_{\text {reg }} \mathrm{S}$ of critical importance for control of HERV-W ENV expression become replaced by $\mathrm{T}$-helper cells with similar specificity $\bullet \bullet \bullet$. The generation and maintenance of the postulated HERV-W ENV suppressive and, as a consequence MS-protective, immune surveillance on the one hand and the replacement of $\mathrm{T}_{\mathrm{reg}} \mathrm{s}$ by $\mathrm{T}$-helper cells on the other will inevitably have a range of observable effects on the immune network and, thereby, on the overall pattern of immune reactivity. These effects include an epitope spreading of the T-helper cell epitope in EBV EBNA1 [13], an elevated antibody level against EBNA1 [11], an attrition of the $\mathrm{CD}^{+}{ }^{+} \mathrm{T}$-cells with specificity for EBV-infected cells though not a reduction of the total number of $\mathrm{CD}^{+} \mathrm{T}$-cells with specificity for EBV [72], and an elevated antibody production against a diverse range of pathogens [15,16]. Those pathogens which appear most strongly associated with the pathogenesis of MS bear the identified candidate target sequences for the $\mathrm{T}_{\text {reg }} \mathrm{S}$ as well as for the $\mathrm{CD}^{+}$effector T-cells on the same protein; namely, measles, varicella, herpes simplex and rubella viruses, the latter only when infection involves the brain, where processing of the viral precursor protein is incomplete. All these exogenous viruses support, by their involvement in the immune network, a MS-protective cellular immune response that becomes compromised before the clinical onset of MS. Again, light is shed on the identity of the candidate epitope of relevance for the MS-protective $\mathrm{CD}^{+} \mathrm{T}$-cells by the postulated analogy to melanoma. In both cases it is a peptide coded for by an additional open reading frame in the gene complex coding for the human endogenous retroviral ENV protein $[14,73]$. The candidate peptide of putative relevance for MS is, surprisingly, coded on the counter-strand of the ENV-coding DNA strand [14]. The candidate mechanism suppressing the activity of HERV-W ENV but inducing a lytic cycle of EBV $[28,29,73]$ seems to operate by causing a shedding of gangliosides of the neo-lacto series to the target cell $[28,29]$.

\section{MLN might explain the relevant mode of action of diverse factors in the aetiology of MS}

In respect to these infective, immunological and other potential MS risk factors, centering on epidemiological observations, a number of questions relevant to the MLN-based concept are raised: Could worm infestation, which has recently been shown to have beneficial effects in MS, be exerting a non-specific immune modulating effect favouring expansion of sub-populations of $\mathrm{T}_{\text {reg }} \mathrm{S}$ [22], with allergic immune reactions being counterproductive [23] $\bullet \bullet$ ? Is a critical involvement of $\mathrm{T}_{\text {reg }} \mathrm{S}$ evidenced by the association of MS to mutations in the IL-7R $\alpha$ gene (CD25 molecule of $\mathrm{T}_{\mathrm{reg}} \mathrm{s}$ ) [26], and the importance of a long-lasting $\mathrm{CD}^{+} \mathrm{T}$ - cell response by mutations in the IL-2R $\alpha$ gene [25]? Moreover, could it be that the set of HLA-antigens of the patients [74] is less 
able to present the peptides that have been delineated and incriminated as essential for the relevant $\mathrm{T}_{\text {reg }} \mathrm{S}$ and effector T-cells of the suggested MS protective immune response [14] $\bullet \bullet \bullet$ ? Could it be that the suggested effector mechanism, a ganglioside-mediated suppression of HERV gene expression [14,19], is reflected in a seemingly protective effect of dietary $\mathrm{n}-3$ polyunsaturated linoic acids that enhance the ganglioside content of $\mathrm{T}$ cells [27]?

Other questions arise concerning additional factors that do not predominantly involve the immune system. Thus, could vitamin D deficiency $[3,33,34]$ as well as a low exposure to bright sunlight rich in UV-B resulting in low intracellular glutathione [35] favour the biogenesis of MLN and play a role in a compromised ability to reduce oxidatively charged MLN $\bullet \bullet$ ? Could a selenium deficiency, another factor linked epidemiologically with a risk of MS [36,37], result in reduced levels of glutathione peroxidase (a selenium-containing enzyme) [38]? Could smoking [40] lead to enrichment of nicotine in melanin containing cells and thus to a disturbance of melanin biosynthesis [41] $\bullet$ ? Could the risk-enhancing influence of female sex hormones be due to a steroid sensitivity of the endogenous retroviral syncytin gene that has a

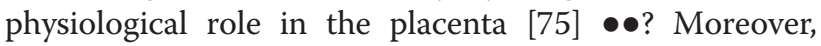
could the hormone melatonin that regulates melanin activity explain a higher rate of MS onset and of attacks in the lighter months of the year $[31,32]$ ?

Could psycho-physical trauma act via mitochondrial production of ROS [52]? Could a reduction of the risk of MS in some regions in birth cohorts since the 1920's be attributable to the introduction of anti-pyretics [53] and, some time later, of antibiotics [55] with their influence on pyogenic infections, since reactive oxygen species and radicals (ROS) are released from mitochondria under the influence of the unphysiological conditions of heat and fever [54] $\bullet$ ? Could it be also that the bulk of NO in the process finally manifesting as MS is produced by peripheral blood adherent mononuclear cells in small blood vessels that can still be seen in the plaques as the pathological end stages of MS [57] $\bullet$ ? The more harmful nitrogen-containing ROS such as peroxynitrite, able to cause demyelination, can, however, be scavenged by uric acid [58] $\bullet$. Interestingly, in this context, MS is extremely rare in patients with gout and the serum concentration of uric acid tends to be about 10-15\% lower in MS patients than in controls [58]. Could a currently used MS remedy, glatiramer acetate, work predominantly as an inhibitor of NO synthases [59]? Finally, light might be shed on what is perhaps the least understood aspect of MS, the question of what is going wrong with the mitochondria and why they have a higher tendency to produce ROS? It has been postulated that there is an activation of the cellular mevalonate pathway in MS with production of endogenous digoxin and a decrease of ubiquitin levels that impairs mitochondrial function and contributes to oxidative stress [56]. The question is raised whether this aberrant mitochondrial function might be caused by abnormal expression and activity of HERVs [76].

\section{Discussion}

The melanin-based concept is a promising and unifying one that could explain several of the enigmas of MS, including the distribution of age at onset since there is only a very small amount of neuromelanin in childhood, in particular in early childhood [45], and also the complex basis of latency and the Belousov-Zhabotinsky characteristic of the spatial and temporal characteristics of the disease (plaques, attacks, remissions) [19,71]. Although many putative factors appear to be involved at the various states of the pathogenesis and clinical manifestation of MS, the generation and maintenance of MLN is, if the hypothesis is correct, likely to be a key feature throughout. Moreover, the concept sheds light, in principle, on a number of epidemiological observations on factors possibly involved in the aetiology of MS, in particular EBV infection, the HLA system, geomagnetic disturbances/cosmic radiation, vitamin D levels, and smoking, as well as several others listed in Table 1. The possible involvement of cosmic radiation $[77,78]$ is an aspect in which interest has been revived [1] and it has been investigated recently in a mouse model of Alzheimer's disease [79]. Although definitive answers cannot be given to any of the many specific questions raised on possible relations to the hypothetical MLN, it should be noted that the concept as a whole is unique amongst the hypotheses on MS in not contradicting the birth cohort trends [2]. Also, as the many factors referred to above vary from region to region and from patient to patient, the involvement of MLN could be a constant feature despite the heterogeneous nature of the disease.

The concept discussed in this debate paper differs markedly from competing hypotheses and from current concepts that are focused on cell-mediated immune reactions directed against myelin. In this context, infiltrating lymphocytes are typically absent in progressing and expanding MS lesions, and there is a prominent oligodendrocyte loss and apoptosis, supporting the concept that the plaque formation has indeed some basis other than cell-mediated immunity against a myelin or oligodendrocyte antigen $[80,81]$. From this concept, and from the conclusions of other workers [82], it now appears that autoimmune reactions in MS are only secondary phenomena.

The unifying concept has many elements that may vary in their impact from patient to patient. Though less 
so for the unifying concept itself, this may be of relevance more for secondary phenomena, such as autoimmune reactions and phenomena associated with the compartmentalisation of iron. Thus the accumulation of iron in MLN may result in a shortage of iron in myelin, which could impair the function of nerve cells [83]. These effects might contribute to the heterogeneity of

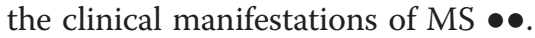

There is certainly a need to study all the diverse aspects of MS in relation to MLN and iron, including the impact of pregnancy [39] and geological terrain of residence [50]. Unfortunately, neuromelanin is not a molecule that is easily studied [43], especially as there is little or no neuromelanin (the precursor of MLN) in the

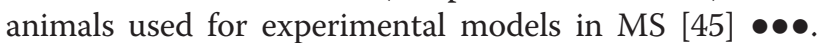
Thus, perhaps, emphasis must be placed on the study on iron in the human brain [84] $\bullet$. While prevention of MS may ultimately depend on the development of an effective vaccine against the Epstein-Barr virus that can be administered in early childhood, as the sine qua non for

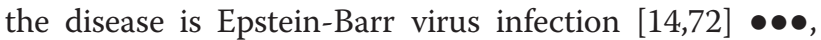
therapy of established MS poses a greater challenge. Addressing this challenge would be greatly facilitated if there is indeed a unifying factor underlying the complexity of the pathogenesis of MS and we open for debate the possibility that this unifying factor is the generation of a melanoma-like neuromelanin.

\section{Summary}

The concept of an abnormal MLN explains many of the characteristics of MS and we postulate that it is an essential feature of this disease. There are many outstanding unanswered questions surrounding the various pathological, immunological and clinical aspects of MS but a consideration of the underlying role of MLN and the processes leading to its generation and maintenance may help to answer these questions and pave the way to a unified concept of the pathogenesis of this complex disease.

\section{Abbreviations}

DNA: Deoxyribonucleic acid; EBV: Epstein-Barr virus; ENV: Envelope protein; HERV: Human endogenous retrovirus; MLN: Melanoma-like neuromelanin; MS: Multiple sclerosis; NO: Nitrogen oxide; ROS: Reactive oxygen species and radicals; $T_{\text {reg }}$ S: Regulatory T-cells.

\section{Competing interests}

The authors declare that they have no competing interests.

\section{Authors' contributions}

BK and JMG contributed equally. Both authors read and approved the final manuscript.

\section{Authors' information}

$\mathrm{BK}, \mathrm{PhD}, \mathrm{MD}$, worked for more than 7 years in the field of biomolecular chemistry on redox pigments of the quinone type and for 22 years in the field of virology. Together with JMG he investigated the possible infectious background of multiple sclerosis and of melanoma, the latter within the frame of the FEBIM studies. JMG, MD, MSc, has worked extensively on the microbiology and immunology of chronic infection, especially tuberculosis, and on the immunology and immunotherapy of cancer.

\section{Acknowledgement}

We thank F Hanefeld, Göttingen, Germany, for valuable discussions.

\section{Author details}

'Institute of Virology, University of Göttingen, Kreuzbergring 57, 37075 Göttingen, Germany. ${ }^{2}$ Medical Laboratory, Kurt Reuber-Haus, Herkulesstraße 34a, 34119 Kassel, Germany. ${ }^{3}$ London Clinic Cancer Centre B2, 22 Devonshire Place, London W1G 6JA, UK.

Received: 6 March 2013 Accepted: 11 July 2013

Published: 18 July 2013

\section{References}

1. Sajedi SA, Abdollahi F: Geomagnetic disturbances may be environmental risk factor for multiple sclerosis: an ecological study of 111 locations in 24 countries. BMC Neurol 2012, 12:100.

2. Ajdacic-Gross V, Tschopp A, Schmid M, Bopp M, Gutzwiller F: Missed epidemics and missing links: international birth cohort trends in multiple sclerosis. Eur J Neurol 2013, 20:440-447.

3. Handel AE, Giovannoni G, Ebers GC, Ramagopalan SV: Environmental factors and their timing in adult-onset multiple sclerosis. Nat Rev Neurol 2010, 6:156-166.

4. Mameli G, Astone V, Arru G, Marconi S, Lovato L, Serra C, Sotgiu S, Bonetti B, Dolei A: Brains and peripheral blood mononuclear cells of multiple sclerosis (MS) patients hyperexpress MS-associated retrovirus/HERV-W endogenous retrovirus, but not human herpesvirus 6. J Gen Virol 2007, 88:264-274

5. Sotgiu S, Arru G, Mameli G, Serra C, Pugliatti M, Rosati G, Dolei A: Multiple sclerosis-associated retrovirus in early multiple sclerosis: a six-year follow-up of a Sardinian cohort. Mult Scler 2006, 12:698-703.

6. Mameli G, Poddighe L, Astone V, Delogu G, Arru G, Sotgiu S, Serra C, Dolei A: Novel reliable real-time PCR for differential detection of MSRV env and syncytin-1 in RNA and DNA from patients with multiple sclerosis. J Virol Methods 2009, 161:98-106.

7. Christensen T: Association of human endogenous retroviruses with multiple sclerosis and possible interactions with herpes viruses. Rev Med Virol 2005, 15:179-211.

8. Christensen T, Petersen T, Thiel S, Brudek T, Ellermann-Eriksen $S$, Møller-Larsen A: Gene-environment interactions in multiple sclerosis: innate and adaptive immune responses to human endogenous retroviruses and herpes virus antigens and the lectin complement activation pathway. J Neuroimmunol 2007, 183:175-188.

9. Antony JM, van Marle G, Opii W, Butterfield DA, Mallet F, Yong WW, Wallace JL, Deacon RM, Warren K, Power C: Human endogenous retrovirus glycoprotein-mediated induction of redox reactants causes oligodendrocyte death and demyelination. Nat Neurosci 2004, 7:1088-1095.

10. Pohl D, Krone B, Rostasy K, Kahler E, Brunner E, Lehnert M, Wagner HJ, Gärtner J, Hanefeld F: High seroprevalence of Epstein-Barr virus in children with multiple sclerosis. Neurology 2006, 67:2063-2065.

11. Haahr S, Höllsberg P: Multiple sclerosis is linked to Epstein-Barr virus infection. Rev Med Virol 2006, 16:297-310.

12. Haahr $\mathrm{S}$, Plesner AM, Vestergaard BF, Höllsberg P: A role of late Epstein-Barr virus infection in multiple sclerosis. Acta Neurol Scand 2004, 109:270-275.

13. Lünemann JD, Edwards N, Muraro PA, Hayashi S, Cohen Jl, Münz C, Martin R: Increased frequency and broadened specificity of latent EBV nuclear antigen-1-specific T cells in multiple sclerosis. Brain 2006, 129:1493-1506.

14. Krone B, Oeffner F, Grange JM: Is the risk of muliple sclerosis releated to the 'biography' of the immune system? J Neurol 2009, 256:1052-1060.

15. Krone B, Pohl D, Rostasy K, Kahler E, Brunner E, Oeffner F, Grange JM, Gärtner J, Hanefeld F: Common infectious agents in multiple sclerosis: a case-control study in children. Mult Scler 2008, 14:136-139.

16. Norrby E: Viral antibodies in multiple sclerosis. Progr Med Virol 1978, 24:1-39.

17. Reiber H, Teut M, Pohl D, Rostasy KM, Hanefeld F: Paediatric and adult multiple sclerosis: age-related differences and time course of the 
neuroimmunological response in cerebrospinal fluid. Mult Scler 2009, 15:1466-1480.

18. Pohl D, Rostasy K, Jacobi C, Lange P, Nau R, Krone B, Hanefeld F: Intrathecal antibody production against Epstein-Barr and other neurotropic viruses in pediatric and adult onset multiple sclerosis. J Neurol 2010, 257:212-216.

19. Krone B, Grange JM: Paradigms in multiple sclerosis: time for a change, time for a unifying concept. Inflammo Pharmacology 2011, 19:187-195.

20. Bagos PG, Nikolopoulos G, loannidis A: Chlamydia pneumoniae infection and the risk of multiple sclerosis: a meta-analysis. Mult Scler 2006, 12:397-411.

21. Höllsberg P, Kusk M, Bech E, Hansen HJ, Jacobsen J, Haahr S: Presence of Epstein-Barr virus and human herpes virus $6 \mathrm{~B}$ in multiple sclerosis: association with clinical activity. Acta Neurol Scand 2005, 112:395-402.

22. Correlae J, Farez M: Association between parasite infection and immune responses in multiple sclerosis. Ann Neurol 2007, 61:97-108.

23. Jadidi-Niaragh F, Mirshafiey A: Histamine and histamine receptors in pathogenesis and treatment of multiple sclerosis. Neuropharmacology 2010, 59:180-189.

24. Chao MJ, Barnardo MC, Lincoln MR, Ramagopalan SV, Herrera BM, Dyment DA, Montpetit A, Sadovnick AD, Knight JC, Ebers GC: HLA class alleles tag HLA-DRB1*1501 haplotypes for differential risk in multiple sclerosis susceptibility. Proc Natl Acad Sci USA 2008, 105:13069-13074

25. Wang LM, Zhang DM, Xu YM, Sun SL: Interleukin 2 receptor a gene polymorphism and risk of multiple sclerosis: a meta-analysis. J Int Med Res 2011, 39:1625-1635.

26. Fang L, Isobe N, Yoshimura S, Yonekawa T, Matsushita T, Masaki K, Doi H, Ochi K, Miyamoto K, Kawano Y, Kira J, South Japan Multiple Sclerosis Genetics Consortium: Interleukin-7 receptor alpha gene polymorphism influences multiple sclerosis risk in Asians. Neurology 2011, 76:2125-2127

27. Lauer K: Diet and multiple sclerosis. Neurology 1997, 49:S55-61

28. Schaade L, Kleines M, Krone B, Hausding M, Walter R, Ritter K: Enhanced transcription of the S-adenosylhomocysteine hydrolase gene precedes Epstein-Barr virus lytic gene activation in ganglioside stimulated lymphoma cells. Med Microbiol Immunol 2000, 189:13-18.

29. Maas D, Maret C, Schaade L, Scheithauer S, Ritter K, Kleines M: Reactivation of the Epstein-Barr from viral latency by an S-adenosylhomocysteine hydrolase/14-3-3 zeta/PLA2-dependent pathway. Med Microbiol Immunol 2006, 195:217-223.

30. Willer CJ, Dyment DA, Sadovnik AD, Rothwell PM, Murray TJ, Ebers GC: Timing of birth and risk of multiple sclerosis: population based study. Br Med J 2005, 330:120-123.

31. Hanefeld F, Krone B: Multiple sclerosis 1st attack peaked in May and June and showed an excess of $30 \%$ from March to August vs September to February. Girl:boy ratio on age at onset in young children ( $<8$ years) was found to be 1.2:1, compared with 3:1 in adults. Data from a German cohort ( $\mathrm{N}=138$ ) with onset of MS in childhood, 1985 to 2002. Personal communication 2013. Unpublished Data.

32. Banwell B, Ghezzi A, Bar-Or A, Mikaeloff $Y$, Tardieu M: Multiple sclerosis in children: clinical diagnosis, therapeutic strategies, and future directions. Lancet Neurol 2007, 6:887-902.

33. Ascherio A, Munger $\mathrm{KL}$ : Environmental risk factors for multiple sclerosis. Part II: noninfectious factors. Ann Neurol 2007, 61:504-513.

34. Munger KL, Levin LI, Hollis BW, Howard NS, Ascherio A: Serum 25-hydroxyvitamin D levels and risk of multiple sclerosis. J Amer Med Assoc 2006, 296:2832-2838.

35. Garcion E, Sindji L, Leblondel G, Brachet P, Darcy F: 1,25-dihydroxyvitamin D3 regulates the synthesis of gamma-glutamyl-transpeptidase and glutathione levels in rat primary astrocytes. J Neurochem 1999, 73:859-866.

36. Häsänen E, Kinnunen E, Alhonen P: Relationship between the prevalence of multiple sclerosis and some physical and chemical properties of soil. Sci Total Environ 1986, 58:263-272.

37. Mehrpou M, Kyani A, Zafazzoli M, Fathi F, Joghataie MT: A metabonomics investigation of multiple sclerosis by nuclear magnetic resonance. Magn Reson Chem 2013, 51:102-109.

38. Shukla VK, Jensen GE, Clausen J: Erythrocyte glutathione perioxidase deficiency in multiple sclerosis. Acta Neurol Scand 1977, 56:542-550.

39. Lee M, O'Brien P: Pregnancy and multiple sclerosis. J Neurol Neurosurg Psychiatry 2008, 79:1308-1311.
40. Handel AE, Williamson AJ, Disanto G, Dobson R, Giovannoni G, Ramagopalan SV: Smoking and multiple sclerosis: an updated meta-analysis. PLoS One 2011, 6:e16149.

41. Yerger VB, Malone RE: Melanin and nicotine: a review of the literature. Nicotine Tob Res 2006, 8:487-489.

42. Double KL, Maruyama W, Naoi M, Gerlach M, Riederer P: Biological role of neuromelanin in the human brain and its importance in Parkinson's disease. In Melanins and melanosomes: biosynthesis, biogenesis, physiological, and pathological functions. Edited by Borovansky J, PA Ridley PA. New York: Wiley-VCH; 2011:225-246.

43. Wakamatsu K, Ito S: Advanced chemical methods in melanin determination. Pigment Cell Res 2002, 15:174-183.

44. Larsson BS: Interaction between chemicals and melanin. Pigment Cell Res 1993, 6:127-133.

45. Borovansky J, PA Ridley PA: Melanins and melanosomes: biosynthesis, biogenesis, physiological, and pathological functions. New York: Wiley-VCH; 2011.

46. Larson B, Tjälve $H$ : Studies on the melanin affinity of metal ions. Acta Physiol Scand 1978, 104:479-484.

47. Hong L, Liu Y, Simon J: Binding of metal ions to melanin and their effects on aerobic reactivity. Photochem Photobiol 2007, 80:477-481.

48. Pavel S, van Nieuwpoort F, van der Meulen H, Out C, Pizinger K, Cetkovská P, Smit NP, Koerten HK: Disturbed melanin synthesis and chronic oxidative stress in dysplastic naevi. Eur J Cancer 2004, 40:1423-30.

49. Kalyanaraman B, Felix CC, Sealey RC: Photoionization and photolysis of melanins: an electron spin resonance-spin study. J Amer Chem Soc 1984, 106:7327-7330.

50. Risberg G, Aarseth JH, Nyland H, Lauer K, Myhr KM, Midgard R: Prevalence and incidence of multiple sclerosis in Oppland county: a cross-sectional population-based study in a landlocked county of eastern Norway. Acta Neurol Scand 2011, 124:250-257.

51. Meier DS, Balashov KE, Healey B, Weiner HL, Guttman CR: Seasonal prevalence of MS disease activity. Neurology 2010, 75:799-806.

52. Mohr DC, Hart SL, Julian L, Cox D, Pelletier D: Association between stressful life events and exacerbation in multiple sclerosis: a meta-analysis. Br Med J 2004, 328:731

53. Edlich RF, Buschbacher RM, Cox MJ, Long WB, Winters KL, Becker DG: Strategies to reduce hyperthermia in ambulatory multiple sclerosis patients. J Long Term Eff Med Implants 2004, 14:467-479.

54. Romberg A, Ikonen A, Ruutiainen J, Virtanen A, Hämäläinen P: The effects of heat stress on physical functioning in persons with multiple sclerosis. J Neurol Sci 2012, 319:42-46.

55. Alonso A, Jick SS, Jick H, Hernan MA: Antibiotic use and risk of multiple sclerosis. Am J Epidemiol 2006, 163:997-1002.

56. Kurup R, Kurup PA: Hypothalamic digoxin, cerebral dominance and brain function in health and disease. New York, USA: Nova Science Publishers; 2009:245-249

57. Hirsch HE, Blanco CE, Parks ME: Fibrinolytic activity of plaques and white matter in multiple sclerosis. J Neuropathol Exp Neurol 1981, 40:271-280.

58. Spitsin S, Koprowski H: Role of uric acid in multiple sclerosis. In Current Topics in Microbiology and Immunology. Edited by Rodriguez M. Heidelberg: Springer; 2008. 318:325-342.

59. Iarlori C, Gambi D, Lugaresi A, Patruno A, Felaco M, Salvatore M, Speranza L, Reale M: Reduction of free radicals in multiple sclerosis: effect of glatiramer acetate (Copaxone). Mut Scler 2008, 14:739-748.

60. Santiago O, Gutierrez J, Sorlozano A, Dios Luna J, Villegas E, Fernandez O: Relation between Epstein-Barr virus and multiple sclerosis: analytic study of scientific production. Eur J Clin Microbiol Infect Dis 2010, 29:857-866.

61. Krone B, Grange JM: Melanoma, Darwinian medicine and the inner world. J Cancer Res Clin Oncol 2010, 136:1787-1794

62. Muster T, Waltenberger A, Grassauer A, Hirschl S, Caucig P, Romirer I, Födinger D, Seppele H, Schanab O, Magin-Lachmann C, Löwer R, Jansen B, Pehamberger $\mathrm{H}$, Wolff $\mathrm{K}$ : An endogenous retrovirus derived from human melanoma cells. Cancer Res 2003, 63:8735-8741.

63. Rook GA: (Ed): The hygiene hypothesis and Darwinian Medicine. Basel: Birkhäuser; 2009

64. Rumzan R, Wang JJ, Zeng C, Chen X, Li Y, Luo T, Lv F, Wang ZP, Hou H, Huang $F$ : Iron deposition in the precentral grey matter in patients with multiple sclerosis: A quantitative study using susceptibility-weighted imaging. Eur J Radio/ 2013, 82:e95-9. 
65. Al-Radaideh AM, Wharton SJ, Lim SY, Tench CR, Morgan PS, Bowtell R, Constantinescu CS, Gowland PA: Increased iron accumulation occurs in the earliest stages of demyelinating disease: an ultra-high field susceptibility mapping study in clinically isolated syndrome. Mult Scler 2013, 19:896-903.

66. Double KL, Dedov VN, Fedorow H, Kettle E, Halliday G, Garner B, Brunk UT: The comparative biology of neuromelanin and lipofuscin in the human brain. Cell Mol Life Sci 2008, 65:1669-1682.

67. Tribl F, Gerlach M, Marcus K, Asan E, Tatschner T, Arzberger T, Meyer HE, Bringmann G, Riederer P: 'Subcellular proteomics' of neuromelanin granules isolated from the human brain. Mol Cell Proteomics 2005, 4:945-947.

68. Ito S, Wakamatsu K: Chemistry of mixed melanogenesis - pivotal roles of dopaquinone. Photochem Photobiol 2008, 84:582-589.

69. Halliwell B, Gutgeridge JMC: Free radicals in biology and medicine. 3rd edition. Oxford, UK: Oxford Science; 1999:198-200.

70. Campbell GR, Mahad DJ: Mitochondria as crucial players in demyelinated axons; lessons from neuropathology and experimental demyelination. Autoimmune Diseases 2011, 2011. Article ID 262847.

71. Quo CF, Wang MD: Quantitative analysis of numerical solvers for oscillatory biomolecular system models. BMC Bioinformatics 2008, 9(Supl 6):S17.

72. Pender MP, Csurhes PA, Pfluger CMM, Burrrows SR: CD8 T cell deficiency impairs control of Epstein-Barr virus and worsens with age in multiple sclerosis. J Neurol Neurosurg Psychiatry 2012, 83:353-354.

73. Krone B, Kölmel KF, Henz B, Grange JM: Protection against melanoma by vaccination with Bacille Calmette-Guérin (BCG) and/or vaccinia: an epidemiology-based hypothesis on the nature of a melanoma risk factor and its immunological control. Eur J Cancer 2005, 41:104-117.

74. Hafler DA, et al: Risk alleles for multiple sclerosis identified by a genome-wide study. N Engl J Med 2007, 357:851-862.

75. Pérot $P$, Montgiraud $C$, Lavillette $D$, Mallet F: A comparative portrait of retroviral fusogens and syncytins. In Cell fusions: regulation and control. Edited by Larsson LI. Dordrecht, Netherlands: Springer; 2011:63-115.

76. Pérot $P$, Mugnier N, Montgiraud C, Gimenez J, Jaillard M, Bonnaud B, Mallet F: Microarray-based sketches of the HERV transcriptome landscape. PLoS One 2012, 7:e40194. Epub 2012 Jun 28.

77. Barlow JS: Multiple sclerosis, geomagnetic latitudes and cosmic rays. Trans Am Neurol Assoc 1960, 85:189-91.

78. Barlow JS: Solar-flare induced increases in sea-level cosmic ray intensities and other geophysical phenomena in relation to multiple sclerosis. Acta Neurol Scand 1966, 42(Suppl 19):118+.

79. Cherry JD, Liu B, Frost JL, Lemere CA, Williams JP, Olschowka JA, O'Banion MK: Galactic cosmic radiation leads to cognitive impairment and increased a $\beta$ plaque accumulation in a mouse model of Alzheimer's disease. PLoS One 2012, 7:e53275.

80. Henderson AP, Barnett MH, Parratt JD, Prineas JW: Multiple sclerosis: distribution of inflammatory cells in newly forming lesions. Ann Neurol 2009, 66:739-753.

81. Prineas JW, Parratt JD: Oligodendrocytes and the early multiple sclerosis lesion. Ann Neurol 2012, 72:18-31.

82. Behan PO, Chaudhuri A: The sad plight of multiple sclerosis research (low on fact, high in fiction): critical data to support it being a neurocristopathy. Inflammo Pharmacology 2010, 18:265-290.

83. Morelli A, Ravera S, Calzia D, Panfoli I: Impairment of heme synthesis in myelin as potential trigger of multiple sclerosis. Med Hypotheses 2012, 78:707-710.

84. Borovansky J: Detection of metals in tissues, cells and subcellular particles. Sb Lek 1997, 98:77-97.

doi:10.1186/1471-2377-13-91

Cite this article as: Krone and Grange: Is a hypothetical melanoma-like neuromelanin the underlying factor essential for the aetiopathogenesis and clinical manifestations of multiple sclerosis?. BMC Neurology 2013 13:91

\section{Submit your next manuscript to BioMed Central and take full advantage of:}

- Convenient online submission

- Thorough peer review

- No space constraints or color figure charges

- Immediate publication on acceptance

- Inclusion in PubMed, CAS, Scopus and Google Scholar

- Research which is freely available for redistribution

Submit your manuscript at www.biomedcentral.com/submit
C BioMed Central 